\title{
EDUCAÇÃO EM SAÚDE A PORTADORES DE GLAUCOMA: uma abordagem Vygotskiana
}

\section{Resumo}

Esse ensaio tem como objetivo discutir a perspectiva vygotskiana como uma nova abordagem para a educação em saúde a portadores de glaucoma. Justifica este modelo teórico pela possibilidade que oferece para a compreensão do sujeito como um ser social, num processo em constante mudança e transformação. Aponta pressupostos teóricos norteadores das ações educativas, correlacionando-os à importância do reconhecimento das emoções, da afetividade e da potencialidade dos sujeitos no enfrentamento da doença e na aderência medicamentosa.

Descritores: educação em saúde; enfermagem; glaucoma

\begin{abstract}
This study has the objective of discussing the Vygotsky's perspective as a new approach for the health education for people with Glaucoma. This theoretical model is justified by the possibility it offers for understanding that the person is a social being within a process of constant change and transformation. It points out theoretical bases for guiding the educational actions, correlating them with the importance of recognizing emotions, affections, and the potentiality of people as they deal with the illness and learn to take the medication.
\end{abstract}

Descriptors:health education; nursing; Glaucoma

Title: Health education for people with glaucoma: an approach based on Vygotsky's perspective

\section{Resumen}

El ensayo tiene como objeto discutir la perspectiva Vygotskiana como un enfoque para la educación de la salud a quienes padecen de glaucoma. Dicho modelo teórico se justifica por la posibilidad que ofrece para comprender al sujeto como un ser social, en un proceso de permanente cambio y transformación. Apunta presupuestos teóricos que orientarán las acciones educativas y los correlaciona a la importancia del reconocimiento de las emociones, de la afectividad y de la potencialidad de los sujetos para arrostrar la enfermedad y seguir la prescripción de las medicinas.

Descriptores: educación de la salud: enfermería; glaucoma

Título: Salud y educación a los afectados por glaucoma: un enfoque Vygotskiano

\section{Introdução}

Há anos a enfermagem utiliza recursos teóricos e metodológicos para educar os indivíduos para a saúde, buscando, junto a essa clientela, construir novos conhecimentos; mudar idéias, crenças e hábitos; facilitar e promover a aderência ao tratamento; entre outras finalidades. Nessa trajetória, importantes trabalhos científicos embasados em grandes mestres da Pedagogia, Psicologia, Filosofia e Educação, trouxeram para a enfermagem novas propostas de programas e ações educativas na área da saúde. Dentre eles, podemos citar o estudo que propõe um processo educativo, para um envelhecer saudável, com mulheres rurais ${ }^{(1)}$.

No processo de envelhecimento, os eventos inerentes ao curso da vida exigem o seu enfrentamento por parte daqueles que vivenciam esse processo. As afecções podem dificultar esse confronto e a busca de soluções, pelas perdas e pela dependência comumente estabelecidas.

Dentre as doenças oftalmológicas que se manifestam no envelhecimento, o glaucoma chama a atenção por tratar-se de uma das causas mais comuns de cegueira no mundo, incluindo o nosso país(2-4). Ele é definido como uma "neuropatia óptica crônica e progressiva, manifesta por escavação do campo visual, na qual vários fatores de risco estão associados, sendo o principal deles a pressão intra-ocular ${ }^{(5: 77)}$.

$\mathrm{Na}$ nossa experiência com idosos glaucomatosos observamos que as alterações relativas à faixa etária, especialmente àquelas relacionadas às perdas, são mediações importantes na significação do glaucoma e, conseqüentemente, intervêm no seu tratamento. Além disso, o desconhecimento que muitos manifestam sobre a doença e a terapêutica medicamentosa tende a dificultar a adesão ao tratamento e, por conseguinte, agravar o prognóstico visual.

Os programas de educação em saúde revelam-se importante recurso para facilitar - na e pela relação com o outro - o desenvolvimento de ações voltadas à prevenção da cegueira e à promoção da saúde. Esses programas, contudo, precisam ser cuidadosamente avaliados pelos profissionais que os realizam, levando-se em conta que as ações do ser humano são constituídas no e pelo meio social, e mediadas pelas alterações inerentes ao envelhecimento.

A perspectiva sócio-histórica de $V_{y g o t s k y}{ }^{(6)}$ aparece recentemente como uma valiosa contribuição para a educação em saúde, uma vez que oferece a possibilidade de compreender o sujeito como um ser social, num processo em constante mudança e transformação. Esse modelo teórico possibilita analisar a significação dos fenômenos numa dimensão simbólica e intersubjetiva. Permite, assim, analisar os sentidos e significados como um processo social da ordem da produção coletiva (sócio-histórica), das inter-relações do cotidiano, e das configurações intra-subjetivas. Nessa perspectiva analítica, os sinais e sintomas manifestados pelo glaucoma refletem uma realidade - a alteração orgânica - e são mediados por significados socialmente construídos, os quais são convertidos em sentidos, na inter-relação com os processos psicológicos superiores (intra-mental).

\section{Objetivo}

Apresentar e discutir a perspectiva vygotskiana como uma nova abordagem para a educação em saúde a portadores de glaucoma.

\section{Abordagem metodológica}

Para subsidiar a proposta do presente estudo utilizamos parte da nossa tese de doutorado realizada com idosos glaucomatosos, na qual analisamos os sentidos e significados que estes sujeitos constroem acerca da doença e da própria

\footnotetext{
* Enfermeira. Professor Assistente Doutor do Departamento de Enfermagem da Faculdade de Ciências Médicas da universidade Estadual de Campinas (UNICAMP)

E-mail do autor: fernanda@fcm.unicamp.br
} 
vida, e a relação entre eles ${ }^{(7)}$. O referencial teórico que orientou a análise foi a perspectiva sócio-histórica de Vygotsky(6).

Em nossa tese de doutorado participaram doze sujeitos de ambos os sexos, ou seja seis homens e seis mulheres, com idade igual ou superior a 60 anos, portadores de glaucoma de ângulo aberto e que estavam em seguimento ambulatorial num hospital universitário. O consentimento livre e esclarecido não foi obtido, uma vez que em 1995, ano da coleta dos dados, ele não era obrigatório para pesquisas desta natureza. Apesar disso, os sujeitos foram consultados sobre a disponibilidade e o seu consentimento para participarem do estudo, sendo-Ihes assegurado o anonimato dos registros. A coleta de dados, na referida tese, foi realizada por meio de entrevistas individuais e abertas, e, posteriormente, de entrevistas grupais. Nelas, o tema central foi a compreensão dos sujeitos a respeito do glaucoma e da própria vida, uma vez que eles vivenciavam o processo de envelhecimento. Os resultados obtidos correspondem à análise (do intertexto e do subtexto) das entrevistas realizadas com um grupo de três sujeitos.

Para o presente estudo extraímos parte da análise, realizada na tese, que melhor vislumbrava a relevância da educação em saúde para os sujeitos entrevistados, articulando este material à problemática dos portadores de glaucoma e aos pressupostos da perspectiva sócio-histórica norteadores das ações educativas. Assim, o texto que se segue apresenta essa discussão, visando a construção de conhecimento acerca do modelo teórico de Vygotsky e a sua contribuição na prática educativa.

\section{A probemática dos portadores de Glaucoma}

Em nossa tese de doutorado optamos pelo glaucoma (primário) de ângulo aberto, levando em conta algumas características, dentre as quais destacamos a sua cronicidade e a ausência de sintomas nos estágios iniciais da doença. A idade avançada também mostrou-se problematizadora, tendo em vista a necessidade do uso permanente de medicamentos para evitar a cegueira, e as dificuldades encontradas para a regularidade terapêutica. Estudos revelam que a prevalência do glaucoma de ângulo aberto aumenta com a idade, especialmente nos indivíduos acima de 60 anos $^{(2,4)}$. Dentre as várias classificações apontadas na literatura, o termo glaucoma é comumente utilizado para o glaucoma primário de ângulo aberto, também conhecido como glaucoma crônico simples(4)

A terapêutica do glaucoma de ângulo aberto é basicamente clínica e consiste na redução da pressão intraocular, prevenção da escavação do nervo óptico e da perda do campo visual e, conseqüentemente, da cegueira. Para tanto são usadas drogas hipotensoras oculares, cujos mecanismos de ação são diversos. Em situações de difícil controle por meio da terapêutica medicamentosa, são indicadas a trabeculoplastia a laser, a iridotomia a laser, ou a trabeculectomia. Por outro lado, se no início do tratamento as fibras ganglionares, que constituem este nervo, já estão lesadas, a perda da visão (parcial ou total) torna-se irreversível.

Apesar das novas drogas, encontradas atualmente no mercado, apresentarem efeitos colaterais menos deletérios ao organismo, a grande maioria ainda desencadeia reações adversas como: ardor e hiperemia ocular, embaçamento visual, diminuição da acuidade visual noturna, sonolência, fadiga inapetência, cefaléia, náuseas, entre outras. Estas manifestações contribuem para o uso irregular ou suspensão dos medicamentos por parte de seus usuários, podendo levar à perda progressiva da visão e, nos estágios finais, à cegueira.

Muitos dos problemas enfrentados pelos usuários do serviço no qual realizamos a nossa tese de doutorado estão relacionados à idade avançada e à dependência estabelecida para o cuidado à saúde. O desconhecimento sobre a doença alimenta idéias errôneas sobre esta afecção. Uma grande parcela espera, através do tratamento, recuperar a visão perdida pela doença e se decepciona na medida em que não obtém melhora da acuidade visual, apesar de seguirem corretamente a terapêutica.

Grande parte desta clientela não segue regularmente o tratamento clínico, o que é revelado pelo uso incorreto ou descontínuo dos colírios e pela abstenção nos retornos médicos. A associação, que estas pessoas estabelecem, entre a irregularidade no tratamento e os fatores físicos e orgânicos e/ou sócio-econômicos evidencia uma relação de "causa e efeito". Entendemos, porém, que não se trata de uma simples relação linear, mas de um processo complexo, mediado pelos significados que elas atribuem à doença e às suas próprias vidas.

Nesse contexto, e acreditando que a concretude do ser humano é feita nas e pelas relações sociais, a doença é compreendida como um fenômeno que, sendo simbólico, é construído nas/pelas pessoas e remete à uma significação. Os sentidos e significados que as pessoas atribuem à doença fundamentam o desenvolvimento de suas ações, de seu comportamento. Nas/pelas relações interpessoais, as pessoas apropriam-se do conhecimento (do outro) e constroem ou reconstroem significados acerca do glaucoma e sobre si mesmas, enquanto portadoras desta doença; estes sentidos norteiam a sua atividade (produtiva) e o seu próprio cuidado.

Frente a essa problemática, acreditamos que a enfermeira possui um papel relevante neste processo de significação, como elemento facilitador para a compreensão acerca do glaucoma, do tratamento e do prognóstico visual. Utilizando-se de ações educativas ela poderá auxiliar os portadores de glaucoma a encontrar formas para enfrentar a doença e os novos eventos, valorizando as suas potencialidades com vistas a elaboração de expectativas em relação à uma melhor qualidade de vida.

\section{Pressupostos norteadores das ações educativas}

O modelo teórico de Vygotsky tem sido, nos últimos anos, cada vez mais utilizado na área da educação e na prática pedagógica. Ainda que pouco conhecido na área da saúde, a nossa tese de doutorado revelou a valiosa contribuição que os postulados de Vygotsky têm para a enfermagem, particularmente na educação em saúde. A esse respeito chamamos a atenção para a perspectiva semiótica - um dos temas centrais na obra de Vygotsky, analisam que embora a biologia possa dar contar da diversidade, da heterogeneidade, e até mesmo da individualidade e da singularidade, ela não dá conta da subjetividade, da reflexividade e da significação, que corresponde a aspectos peculiares e específicos da condição humana, e que são iniciados na e através da linguagem ${ }^{(8)}$.

Contudo, é preciso cuidado para evitar que uma leitura superficial e reducionista da obra de Vygotsky leve ao uso incorreto e equivocado de suas idéias e pressupostos. Oliveira ${ }^{(9)}$ alerta para a tendência dos educadores em desejar extrair das teorias um "como fazer" eficiente, o que, segundo a autora, faz parte do empreendimento pedagógico. Dessa forma, destaca que, particularmente em Vygotsky(6), "a teoria pode alimentar a prática mas não fornecer instrumentos metodológicos de aplicabilidade imediata"(9:12).

Assim, reiterando a inviabilidade de programas e modelos pré-fabricados pretendemos, nesse momento, apontar alguns pressupostos da perspectiva vygotskiana, correlacionando-os aos achados mais relevantes em nosso estudo com idosos portadores de glaucoma, que possam subsidiar as ações educativas em saúde.

1. No desenvolvimento do sujeito concreto,

o pensamento propriamente dito é gerado pela motivação, isto é, por nossos desejos e necessidades, nossos interesses e emoções. Por trás de cada pensamento há uma tendência afetivo-volitiva que traz em si a resposta ao último 'por que' de nossa análise do pensamento"(6:129). 
Apesar de Vygotsky não ter desenvolvido este pressuposto, os textos escritos por ele e que abordam as emoções e os afetos, podem contribuir para o estudo dos processos conscientes e inconscientes, e do papel da afetividade na constituição da subjetividade humana. Para estas autoras, "o processo cognitivo nunca existe independente da emoção. O que ocorre é que às vezes ela fica encoberta e torna-se difícil o seu reconhecimento"(10:117)

O nosso estudo mostrou que a significação do glaucoma, nos sujeitos entrevistados, é mediada por um sentido dominante que corresponde ao medo da cegueira, da incapacidade, e da dependência. Nesta perspectiva a capacidade para suportar as tensões varia de indivíduo para indivíduo e mantém uma relação direta com a motivação expressa pelos sujeitos e a segurança deles próprios ${ }^{(11)}$.

Considerando que nos serviços de saúde, de um modo geral, ignora-se a história de vida e as necessidades das pessoas que procuram a assistência, a relação entre elas e os profissionais da equipe de saúde deve ser revista e reavaliada, buscando-se analisar a motivação e a afetividade que orientam a reconstrução de sentidos e significados, e a reorganização de suas potencialidades no enfrentamento das afecções, dos novos eventos, e das transformações inerentes no curso da vida. Identificar e reconhecer as emoções e as potencialidades dos sujeitos, a nosso ver, constituem condições essenciais para a educação em saúde.

2. A emoção, que está vinculada ao sentido de cada experiência, em particular, responde às expectativas do sujeito na inter-relação com o outro. A qualidade da inter-subjetividade depende da relação que o outro mantém com o motivo, o qual, em nosso estudo correspondeu à necessidade de atenção e carinho que os idosos esperam receber dos profissionais da área da saúde. Na perspectiva sócio-histórica, a intersubjetividade é compreendida como "o lugar do encontro, do confronto e da negociação dos mundo de significação privados (ou seja, de cada interlocutor) à procura de um espaço comum de entendimento e produção de sentido, mundo público de significação"(12:22). Corresponde, assim, a um campo simbólico, representacional.

Assim, "a comunicação, apesar de ser um espaço real, que resulta da relação do sujeito com os outros, tem, por sua vez, um caráter personalizado, dado que, em seu sentido subjetivo, o sujeito e a satisfação de suas necessidades, desempenham um papel essencial"(13:79). No processo comunicativo, os sujeitos necessitam criar um espaço comum que garanta um sentido positivo e uma motivação compartilhada que permita expressar os interesses pessoais dos participantes desta relação. A satisfação das necessidades dos sujeitos, a atenção que eles esperam receber ao buscar informações sobre a doença, e o desejo de ser reconhecido pelo outro como ativo e interativo, estimula a potência de ação e favorece a aderência ao tratamento.

Ser reconhecido pelo outro (qualquer que seja ele), como ativo, interativo e empenhado em conhecer a sua doença possibilita aos sujeitos a emergência de novas emoções e necessidades, num estado dinâmico de reorganização das experiências e de seu enfrentamento. Estas considerações revelam-se importantes nas ações educativas em saúde, nas quais é fundamental o reconhecimento da constituição subjetiva dos sujeitos - a subjetividade - e, por conseguinte, a intersubjetividade.

É preciso, contudo, que se estabeleça uma comunicação na qual se obtenha uma qualidade afetiva, com partilha da motivação entre os seus interlocutores, numa dinâmica que possibilite a emergência de novas necessidades e emoções.

Assumindo o pressuposto de que a produção de sentidos e a construção de conhecimentos implica numa ação partilhada, na dinâmica das relações interpessoais, particularmente nas ações educativas em saúde, o papel do profissional não pode ser o de agente exclusivo de informação, mas de um parceiro privilegiado(2), tendo em vista os conhecimentos construídos e as experiências vividas em sua vida profissional. Na dinâmica da educação à saúde, não cabe ao profissional "dar sempre a resposta pronta" ${ }^{3}$ às indagações da clientela assistida. Utilizar recursos como: fornecimento de pistas, instruções, demonstrações, assistência, entre outros que facilitem a emergência de interesse, motivação e criatividade, possibilitam formas de confronto, negociação, construção e apropriação de conhecimentos, e de transformação.

3. No processo de interlocução "os modos de configuração de objetos de conhecimentos implicam modos diferenciados de ações e elaborações dos sujeitos em interação (apresentação, apropriação, negociação, etc.)"(14:58-59), o que leva a autora a considerar o jogo de lugares e posições na trama social. Aponta, assim, que "é nesse jogo de posições, lugares, perspectivas, vozes, pressuposições, enunciações, convergências e diferenças que os sujeitos se constituem (são interpelados como tais) e múltiplos sentidos se produzem"(14:58-59).

Em nosso estudo, o encontro com os sujeitos em momentos e situações distintas (entrevista individual e grupal) revelou como a retórica do discurso muda de acordo com a inter-subjetividade. Nesse movimento aparecem ambigüidades e contradições, reveladas pelas mudanças nos significados e pelo papel que o sujeito assume na inter-subjetividade. Isso nos leva a considerar como relevante, nos grupos de educação em saúde, um encontro individual com os participantes, previamente à reunião em grupo. Esse encontro possibilita a emergência de sentidos e significados que podem ser distintos daqueles expressos posteriormente na reunião dos sujeitos com seus pares.

Na educação em saúde é preciso, ainda, cuidado para não menosprezar a capacidade cognitiva dos participantes, mas considerar as suas individualidades, motivações e potencialidades. A idade cronológica, bem como o grau de instrução educacional, não representam limites para a restrição de informações sobre a doença; assim, o direito ao conhecimento sobre a doença e o seu prognóstico deve ser respeitado e valorizado.

O respeito à autonomia e à individualidade é fundamental para o envolvimento das pessoas nas ações educativas em saúde. Por outro lado, recomendamos cautela para não transformar a autonomia e a individualidade em individualismo, o que ocorre quando se acentua a subjetividade como qualidade independente da inter-subjetividade face a face, culpabilizando o indivíduo pelo seu fracasso em cuidar de si, e acentuando o descompromisso com a solidariedade.

\section{Considerações finais}

A utilização dos construtos teóricos de Vygotsky ${ }^{(6)}$ na educação em saúde é, ao mesmo tempo, desafiadora e apaixonante. A complexidade e a falta de clareza em muitos de seus textos tendem, de maneira equivocada, a considerar este modelo teórico inacessível a outras áreas de conhecimento, como por exemplo a educação em saúde. Entretanto, dada a crescente penetração dos trabalhos de Vygotsky ${ }^{(6)}$ no Brasil, atualmente podemos contar em nosso meio com vários estudos e pesquisas nessa perspectiva, os quais facilitam a leitura e a compreensão da sua obra.

Para os que buscam um modelo que oriente passo a passo "o quê" e "como fazer", indicando os possíveis erros e acertos, a perspectiva de Vygotsky pode ser desprezada pela ausência de recursos metodológicos. De fato, a sua proposta nunca foi apresentar um roteiro de procedimentos, mas apontar construtos teóricos para a compreensão do homem como sujeito atrelado às determinações de sua estrutura biológica e de sua conjuntura histórica. Foi com este propósito que 
elaboramos este ensaio, esperando mobilizar os enfermeiros e outros profissionais da saúde a assumir esse novo desafio e descobrir novas formas de compreender o ser humano, como sujeito que tem necessidades e motivações, e partilhar com ele a busca de recursos para o enfrentamento da doença e dos novos eventos inerentes no curso da vida.

\section{Referências}

1. Portella MR. Cuidar para um envelhecer saudável: a construção de um processo com mulheres rurais. Revista Brasileira de Enfermagem, Brasília (DF) 1999 jul/set;52(3):355-64.

2. Gerali PS, DiVerde M. Glaucoma high risk alert. Journal of Ophthalmic Nursing and Technology, Thorofare (NJ) 1991 Jan/Feb;10(1):34.

3. Medina NH, Barros OM; Muñoz EH; Magdaleno RL, Barros AJD, Ramos LR. Morbidade ocular em idosos da cidade de São Paulo - SP, Brasil. Arquivos Brasileiros de Oftalmologia, São Paulo 1993 out;56(5):2768, 281-3.

4. Costa VP, Almeida GV, Kara-José N. Prevenção da cegueira por glaucoma. Arquivos Brasileiros de Oftalmologia, São Paulo 1998 maio/jun;61(3):356-60.

5. Cohen R, Almeida GV. Glaucoma de ângulo aberto. In: Susanna Junior R. Glaucoma. Rio de Janeiro: Cultura Médica; 1999. 298 p. p. 77-122

6. Vygotsky LS. Pensamento e linguagem. $3^{\mathrm{a}}$.ed. São Paulo: Martins Fontes; 1993. 135 p.

7. Cintra FA. A significação do glaucoma e a mediação dos significados de velhice na perspectiva vygotskiana: subsídios para a educação à saúde [tese de Doutorado]. São Paulo: Escola de Enfermagem, Universidade de São Paulo; 1998. 210 f.

8. Smolka ALB, Góes MCR; Pino A. (In)determinacy and the semiotic constitution of subjectivity. In: Fogel A, Lyra MC, Valsiner J, editores. Dynamics and indeterminism in developmental and social processes. Hillsdale (NJ): Ablex; 1997. 195p. p. 153-64.

9. Oliveira MK. O pensamento de Vygotsky como fonte de reflexão sobre a educação. In: Oliveira MK, organizador. Implicações pedagógicas do modelo histórico-cultural. $2^{\mathrm{a}}$ ed. Campinas (SP): UNICAMP; 2000. 113 p. p.11-8. (Cadernos CEDES; 35).

10. Lane STM, Camargo D. Contribuição de Vigotski para o estudo das emoções. In: Lane STM, Sawaia BB, organizadores. Novas veredas da psicologia social. São Paulo: EDUC; 1995. 168 p. p. 115-31.

11. Rey FG. Personalidad, salud y modo de vida. México: UNAM; 1993. $162 \mathrm{p}$.

12. Pino A. Processos de significação e constituição do sujeito. Temas em Psicologia [da SBP], Ribeirão Preto (SP) 1993;1(1):17-24.

13. Rey FG. Comunicación, personalidad y desarrollo. Habana: Pueblo y Educación; 1995. 139 p.

14. Smolka ALB. Conhecimento e produção de sentidos na escola: a linguagem em foco. In: Oliveira MK, organizador. Implicações pedagógicas do modelo histórico-cultural. $2^{\mathrm{a}}$ ed. Campinas (SP): UNICAMP; 2000. 113 p. p. 50-61. (Cadernos CEDES; 35).

Data de recebimento: 23/02/2003

Data de aprovação: 20/08/2003 